NASA Technical Memorandum 101963

\title{
The Solid Surface Combustion Space Shuttle Experiment Hardware Description and Ground-Based Test Results
}

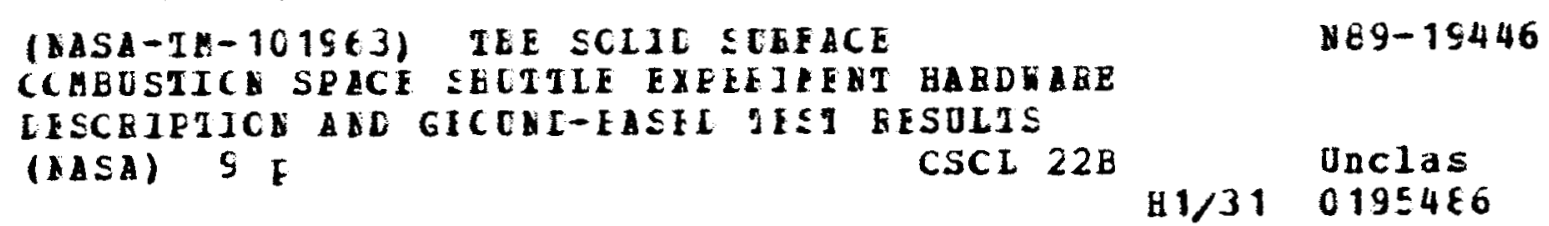

D.M. Vento, R.J. Zavesky, and K.R. Sacksteder

Lewis Research Center

Cleveland, Ohio

and

R.A. Altenkirch

Mississippi State University

Mississippi State, Mississippi

Prepared for the

27th Aerospace Sciences Meeting

sponsored by the American Institute of Aeronautics and Astronautics

Reno, Nevada, January 8-12, 1989

\section{Nush}




\title{
THE SOLID SURFACE COMBUSTION SPACE SHUTTLE EXPERIMENT HARDWARE DESCRIPTION AND GROUND-BASED TEST RESULTS
}

\author{
D.M. Vento, R.J. Zavesky, and K.R. Sacksteder \\ National Aeronautics and Space Administration \\ Lewis Research Center \\ Cleveland, Ohio 44135 \\ and \\ R.A. Altenkirch \\ Mississippi State University \\ Mississippi State, Mississippi 39762
}

\begin{abstract}
The Lewis Research Center is developing a series of microgravity combustion experiments for the Space Shuttle. The Solid Surface Combustion Experiment (SSCE) is the first to be completed. SSCE will study flame spreading over thermally thin fuels (ashless filter paper) under microgravity conditions. The flight hardware consists of a combustion chamber containing the sample and a computer which takes the data and controls the experiment. Experimental data will include gasphase and solid-phase temperature measurements and motion pictures of the combustion process. Flame spread rates will be determined from the motion pictures.
\end{abstract}

\section{Introduction}

The Solid Surface Combustion Experiment (SSCE) is the first of a series of microgravity combustion Space Shuttle experiments being implemented by the Lewis Research Center. Intended to be a pathfinder for the other experiments, SSCE's hallmark is simplicity. Design philosophy for the experiment is to achieve high quality science return without overcomplicating the hardware design. Originated from a concept by the Principal Investigator, Dr. R. A. Altenkirch, the experiment is designed to provide data on flame spreading over solid surfaces in a microgravity environment under quiescent conditions.
Phase I of the experiment is to examine the first of two important geometrical configurations, the thermally thin case, using ashless filter paper as the fuel. In the second phase, SSCE will study thermally thick fuel, using polymethylmethacrylate (PMMA) as the sample material. The microgravity environment afforded by the Space Shuttle is uniquely capable of providing both suitable microgravity conditions and the time duration necessary to conduct the experiment.

This paper describes historical background of the SSCE. The Science Requirements for SSCE are summarized and the resulting hardware is described. Preliminary research data taken during drop tower testing of the SSCE hardware is also presented. In-space operations and Shuttle accommodations are described. Lessons learned during the development of SSCE are described, including verification plans, microgravity testing, software, and Shuttle integration and safety.

\section{Background}

The NASA Lewis Research Center (LeRC) has been involved in microgravity combustion research since the late 1960's. The early research efforts consisted of drop tower experiments performed in response to fire-safety issues raised in the Apollo program. The initial fire-safety work led to other fundarnental questions concerning combustion phenomena under extended periods of 
reduced gravity. Early experimental and analytical microgravity combustion research at LeRC involved gas-jet diffusion flames, flame spread over solid surfaces, and a determination of the effect of chemical inhibitors on flame extinguishment on board the Space Shuttle Orbiter.

LeRC researchers recognized that the extended periods of microgravity available on the Space Shuttle Orbiter could provide a unique laboratory environment for combustion research. The absence of any significant gravitational field facilitates observation of fundamental combustion mechanisms that cannot be directly observed in earthbound experiments because of gravitational settling or buoyancy driven convection processes. The understanding of combustion processes in terrestrial systems, particularly processes involving diffusion, can be enhanced by this research because data from the microgravity experiments can be compared to the analytical predictions of models with the gravity controlled factors removed. Clean experiment boundary conditions can also be uniquely obtained in the near absence of gravity.

As a result of the above activities, LeRC researchers began an intensive effort to identify key fundamental combustion flight experiments and appropriate investigators for those experiments. One of the experiments, involving solid surface combustion. was proposed by Dr. R. A. Altenkirch then of the University of Kentucky, as a part of NASA's PACE (Physics and Chemistry Experiments) Program. After an external peer review, the LeRC researchers recommended the Solid Surface Combustion Experiment for flight, and proposed the experimental hardware described in this paper.

\section{Science Requirements For SSCE}

For flame spread over solid surfaces in a quiescent environment, two important geometrical configurations arise. In the first case, termed thermally thin, the fuel is is too thin to support a temperature gradient across its thickness, and the dominant heat transfer mode becomes gas phase conduction ahead of the flame. This is shown in Figure 1 which depicts the downward flame spread process under normal gravity conditions. In the second case, the thermally thick case, the fuel is thick enough for a transverse temperature gradient to occur, and solid phase conduction becomes important to forward heat transfer. Under microgravity conditions, natural convection is severely curtalled and fuel/air mixing depends on the secondary mechanisms of the local Stefan flow and molecular diffusion.

For the first phase of the flight program, the thermally thin case will be studied using ashless filter paper as the fuel. A variety of environmental conditions inside the combustion chamber will be tested. The test matrix, presented in Table 1, lists the oxygen concentration and the pressure for the first five test points, and was determined following a series of microgravity tests in the Lewis Research Center Zero Gravity Facility (5-second drop tower). The second experiment phase will cover the thermally thick case using PMMA as the fuel, where the exact conditions for the test matrix remain to be determined through a series of ground-based microgravity experiments.

The dimensions and aspect ratio of the paper sample are determined by heat loss considerations. The sample width is adequately large such that heat losses from the llame and fuel to the sample holder do not penetrate to the middle of the sample. A flat flame front in the center region indicates independence of the flame spread rate from the edge effects. Paper sample dimensions are $10.0 \mathrm{~cm}$ long by $3.0 \mathrm{~cm}$ wide by $0.018 \mathrm{~cm}$ thick. The combustion chamber volume is determined by a requirement that oxygen consumption, even by the PMMA samples, will not exceed $5 \%$ of the original amount. Both gas-phase and fuel-surface temperatures must be measured during the experiment.

Motion picture data of two orthogonal views of the spreading flame are required. The top view of the fuel surface shows the leading edge of the spreading flame, and shows the extent of sample holder edge effects. The side view provides the detailed structure of the spreading flame.

\section{General Description of SSCE Flight Hardware}

The SSCE hardware, shown in Figure 2, consists of two modules, a combustion chamber module and a camera module, configured in a block of four Middeck locker spaces as shown in Figure 3. 
Chamber Module

The SSCE combustion chamber containing an ashless filter paper sample is shown in Figure 4. The chamber volume was chosen to accommodate both the paper sample, shown mounted to its holder in Figure 5, and the PMMA sample (yet to be developed), minimizing oxygen depletion during an experiment. To meet flammability restrictions, the chamber windows are made from "Lexan" polycarbonate bonded to optically clear sapphire, with the sapphire surface on the interior of the chamber. Environmental conditions up to $98 \%$ oxygen can be provided inside the chamber without causing a flammability hazard for any chamber materials. The operating pressure of the SSCE chamber is two (2) atmospheres and the chamber is hermetically sealed.

During a Shuttle mission only one sample is to be burned in each chamber and the chamber is not to be opened. This important design decision is consistent with the "keep it simple" design philosophy and avolds the significant complications of overboard venting, replacement-atmosphere pressure bottles, and opening the chamber to the cabin atmosphere. Additional samples can be tested only with a chamber exchange where the enture chamber is removed from its baseplate and replaced by another chamber.

Each chamber is held to its baseplate by four bolts which are captive in the chamber legs. A unique code number is electrically wired into the connector of each chamber which enables the data acquisition and control system to recognize which chamber is being used. Stowage for film magazines is provided in a magazine holder on each chamber, thus keeping a particular sample and its film data record together.

Sample Holder. Fuel samples for the combustion experiments are held in a sample holder mounted along the long dimension of the chamber as shown in Figure 4. Paper samples are clamped between two metal plates, as shown in Figure 5. Three thermocouples are used for each test specimen. One thermocouple is used to obtain solid phase temperature and is actually embedded into the paper sample. The other two thermocouples are used to obtain gas-phase temperatures and are suspended above the paper at heights of $3 \mathrm{~mm}$ and $5 \mathrm{~mm}$, respectively. A pressure transducer mounted to the crosspiece holding the paper sample is used to measure chamber pressure before and during the experiment.
The SSCE paper ignitor combines both an electrical and a chemical ignition technique. As shown in Figure 5, a nichrome wire is attached to the paper sample at one end. A coating of nitrocellulose is painted over the wire on one side of the sample. When a two (2) ampere current is applied to the nichrome wire, resistance heating ignites the nitrocellulose which in turn ignites the paper. This ignition technique is designed to provide high reliability and to minimize the amount of excess heat that is added to the system.

The modular design of the sample holder simplifies the conversion of SSCE to other types of fuel. In a proposed second phase to SSCE, a thermally thick geometry will be studied using PMMA as the fuel.

\section{Camera Module}

The Camera Module contains the data acquisition and control system, a battery pack, two movie cameras, and an electrical power filter for the cameras as shown in Figure 6. A "mast" is used to hold the cameras in such a way that one camera views the top of the sample and the other views the side of the sample. The other components of the Camera Module are arranged around the cameras.

Data Acquisition and Control System. SSCE uses an STD-Bus microcomputer system with a total of six boards for all data and control functions as shown in Figure 7. The CPU is an NSC 800 microprocessor and is supported by a memory board with $40 \mathrm{~K}$ Bytes of EEPROM for storing data. Two A/D converter boards are used, one for high-level (5 VDC) data and one for millivolt-level data. $1 / O$ is provided by an RS-232 board and by a custom built STD-Bus board which controls the sample ignitor and the indicator lights on the control panel.

The SSCE has two data acquisition modes. In the fast data-rate mode, the thermocouples are sampled at 20 samples per second, using a 12 bit $A / D$ converter. The slow data-rate mode takes data (also 12 bits resolution) from the thermocouples, cabin-temperature sensor and a chamber-pressure transducer at two (2) samples per second. Fast data is taken for one minute after ignition of the sample. Slow data is taken before and after the combustion experiment.

Optical System. Two views of the experiment are provided by the optical system, using two $16 \mathrm{~mm}$ 
movie cameras, as shown in Figure 6. The top view of the sample is provided by the upper camera. and the side view is provided by the lower camera. The cameras are fixed, and the entire test sample is within the field of view of the cameras. Spatial resolution of less than $0.1 \mathrm{~mm}$ is obtained with this system. The cameras. PhotoSonics Model $16 \mathrm{~mm}-1 \mathrm{VN}$, have removable film magazines. During a mission, the film magazines for a given sample are stored in a holder attached to the combustion chamber. Film magazines are changed out and remain with the corresponding combustion chamber.

\section{Research Results}

Because so little is known about low-gravity combustion phenomena, the design of in-space combustion experiments requires ground-based verification testing of subsystems and components that depend on low-gravity combustion behavior. Candidate components for the SSCE ignition system and sample-preparation procedures were tested in a series of 5-second drop tower tests. The test results provide some scientific insight useful both in the flight hardware design and in advancing the understanding of low-gravity flame spreading.

The ignition process, just as the flamespreading process, includes the finite-rate vaporization of the fuel surface. In low-gravity, the fluid motion assoclated with vaporization (a Stefan flow) influences the flame-spread rate. Ignition techniques that induce excessive fluid motion would disturb the flame spreading experiment and must be curtalled. Thus drop-tower ignitions can only be initiated after the onset of free-fall to prevent normal-gravity buoyant flows from disturbing the experiment. Similarly, the amount of nitrocellulose ignition enhancer added to ensure ignition must be limited so that the ignition flash is no larger than the expected low-gravity flame.

The ignition event consumes as much as 1.5 seconds of the available 5 seconds. The remaining 3.5 seconds are inadequate under any oxygen fraction conditions for the flame to move out of the thermal influence of the ignition system. Uncertainty in the interpretation of the test results follows in two forms. The flame spread rate measured in each test shows significant scatter for each test condition:
O2 \% Press. (atm.) Spread Rate (cm/sec)

$\begin{array}{lll}30 & 1.0 & 0.30-0.40 \\ 30 & 1.5 & 0.18-0.35 \\ 50 & 1.5 & 0.31-0.47\end{array}$

In addition, the intensity of low-gravity flame luminosity cannot be isolated because of the thermal contribution of the ignition system. These results indicate the need to reduce the ignition time to a minimum in subsequent tests to provide more time for the low-gravity behavior to develop.

\section{In-Space Operations}

Operation of SSCE. Operation of the experiment is semi-automatic. The Mission Specialist must first mount the film magazines for the first sample. Next, the circuit breakers on the battery pack and the electrical box are switched on. This action causes a series of LEDs on the control panel to light up, and causes the data system to initialize. When the indicator light signals that the experiment is ready, the Mission Specialist presses the experiment start button, activating the experiment. After completion of an experiment, power is switched off, and the film magazines are stowed in the magazine holder on the combustion chamber. The chamber can then be removed from its baseplate and replaced by the next sample chamber. A maximum of three chambers can be accommodated per flight.

Flight Accommodation. The SSCE can be located in the Middeck locker area or a SMIDEX rack. In the Middeck configuration, a minimum of four locker spaces are required and arranged in a two by two locker array, as shown in Figure 3 . If more than one test is to be conducted on a mission, two locker spaces are required for each additional chamber. Thus if three chambers are to be used on a single flight, a total of eight locker spaces are required. On a Spacelab mission, SSCE can fly in the middeck, SMIDEX, or center aisle.

\section{Lessons Learned}

Safety Considerations. Safety considerations must be given the highest priority by experiment 
designers from the very beginning of the design process. The requirements from NHB 1700.7. KHB 1700.7, and the experiment Interface Control Document (see references), should be viewed as additional design requirements by the designers along with the science requirements and the technical requirements.

Verification Plan. Careful planning is critical to success for a small experiment. Potential problems need to be identified early in the project life cycle. A strong verification plan, produced very early in the design phase, forced the SSCE project team to recognize most of the development items early in the design phase. For example, early vibration testing was conducted on sample holder design concepts to develop the thermocouple mounting system for the paper, and to develop a paper-sample configuration which could survive the Shuttle launch vibrations. Over 100 vibration tests were conducted to perfect the sample holder prior to preliminary design. Normally, vibration tests would not be conducted until either a prototype or qualification unit is completed. This testing would normally occur very late in the project life cycle, and would seriously impact the schedule should problems arise.

Microgravity Testing. Whenever feasible, flight type hardware (e.g. a high fidelity engineering unit) should be tested under microgravity conditions in drop towers or aircraft. Much valuable information about an individual microgravity experiment can be gained in thorough ground based testing. Several important discoveries were made about the SSCE samples and test matrix during what was anticipated as routine testing of the ignition system hardware in the Lewis Zero Gravity Facility. Sample preparation for ashless filter paper was found to be critical. If the paper is not completely dried via vacuum drying during processing, it will not ignite at all in near flammability-limit conditions. During the drop tests, it was also discovered that the original SSCE test matrix, which included test points in a $21 \%$ oxygen environment, was not viable. As a result, the Principal Investigator adopted the test matrix shown in Table 1, which requires higher oxygen concentrations. Subsequent evaluation of the films from drop tests indicate that the camera exposure settings, including frame rate and f stop, need to be changed for flight from what was originally specified in the Science Requirements Document.

Software. The details of the software development process can be ignored until they become severe problems. At the start of the project, the SSCE hardware and software was considered state-ofthe-art. Several schedule delays on SSCE were attributable to the software. Compllers, development systems, computer equipment, and all necessary support software should be obtained before the software development process is even started. Software testing is also important, as equipment often needs to be built that is specific to the project, such as "black boxes" for simulating the experiment. An effective software development plan and configuration control plan can help to alleviate these problems by forcing a project to plan in advance.

EMI/RFI. Motion picture cameras can be a severe source of EMI. The SSCE cameras, which passed RFI testing with excellent results, had conducted noise problems which were not detected until the flight hardware was nearly complete. A filter was designed and added to the flight hardware. Conducted noise problems should be anticipated early in the design process and components suspected of being noisy should be tested.

Shuttle Interfaces. Shuttle interface specifications should not be assumed to be unchanging. The Middeck Interface Control Document originally guaranteed a stiff $28 \mathrm{VDC}$ power source to an experiment regardless of the load, up to the maximum allowable 200 watts. History, however, has shown that the bus voltage actually drops steeply with load, and can go as low as $24 \mathrm{VDC}$ when loaded at 90 watts. The Middeck ICD has been changed to reflect this fact. The lower bus voltage is too low for the SSCE cameras to operate and as a result, SSCE has added a battery pack in order to be isolated from the Shuttle power system.

\section{Concluding Remarks}

The SSCE flight hardware has been completed and at the time of this writing is planned to fly both as a Middeck experiment and on several Spacelab missions as a SMIDEX rack experiment. SSCE has shown that through careful planning, a small scientific experiement can succeed in an uncertain environment. Problems can be overcome through a strong verification plan, careful testing, and effective PI-Project communications. Above all, technology development should be completed prior to any detall design work for the flight hardware. 


\section{$\underline{\text { References }}$}

Science Requirements Document for the Solid Surface Combustion Experiment, University of Kentucky Research Foundation and NASA Lewis Research Center, 1985.

NHB 1700.7A Safety Policy and Requirements for Payloads Using the Space Transportation System, National Aeronautics and Space Administration, December 9, 1980.

KHB 1700.7A Space Transportation System Payload Ground Safety Handbook, National Aeronautics and Space Administration, November 30, 1984.

ICD 2-1 MOO1 Orbiter Middeck/Payload Standard Interfaces Control Document, National Aeronautics and Space Administration, March 1984.

\section{Table 1}

Science Matrix

Set of Experimental Conditions for SSCE Flight Experiments

\begin{tabular}{cccc}
\hline Exp. No. & Fuel & \% Oxyen & $\begin{array}{c}\text { Absolute } \\
\text { Pressure }\end{array}$ \\
1 & Paper & 50 & 1.5 ATM \\
2 & Paper & 30 & 2.0 ATM \\
3 & Paper & 30 & 1.5 ATM \\
4 & Paper & 50 & 1.0 ATM \\
5 & Paper & 30 & 1.0 ATM \\
6 & PMMA & $\mathrm{X}$ & $\mathrm{X}$ \\
7 & PMMA & $\mathrm{X}$ & $\mathrm{Y}$ \\
8 & PMMA & $\mathrm{Y}$ & $\mathrm{Y}$ \\
& $\begin{array}{l}\text { For all experiments, the diluent in the } \\
\text { oxidizing atmosphere is nitrogen, and } \\
\text { one thickness of each fuel is required. }\end{array}$ \\
\end{tabular}

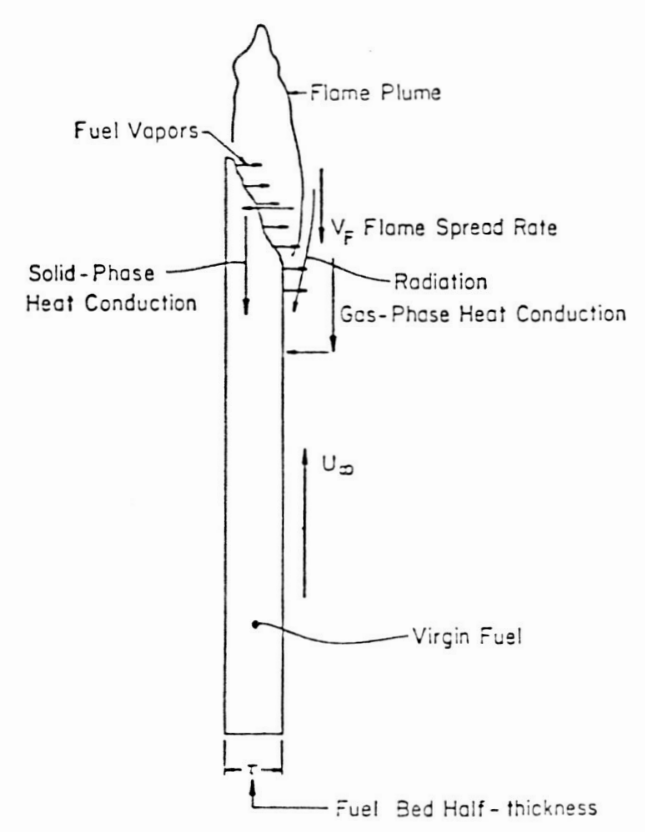

Figure 1 Downward spread process, normal gravity.

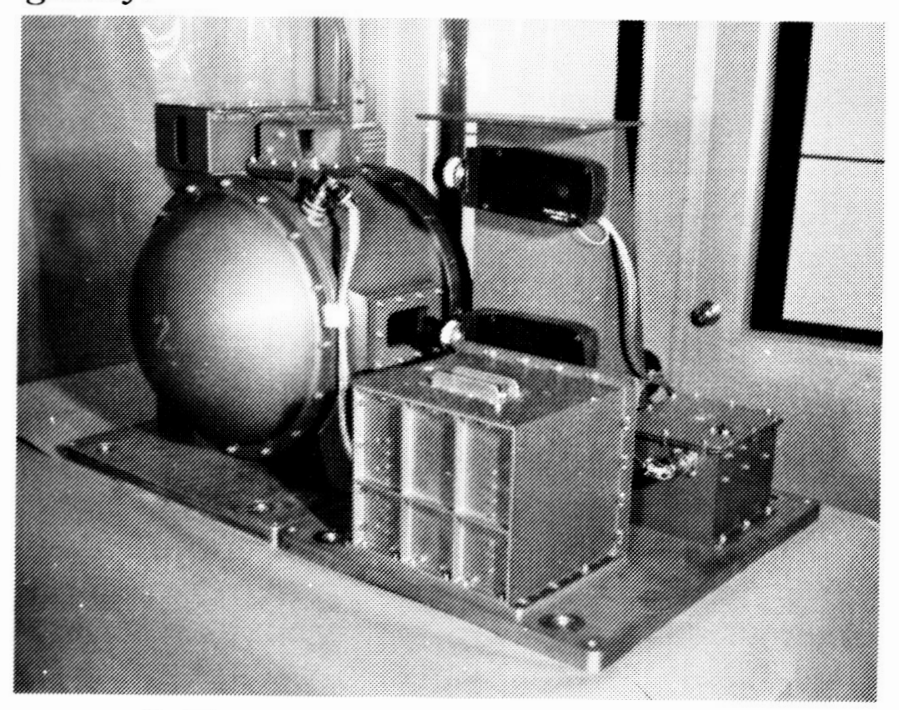

Figure 2 The SSCE Flight Hardware.

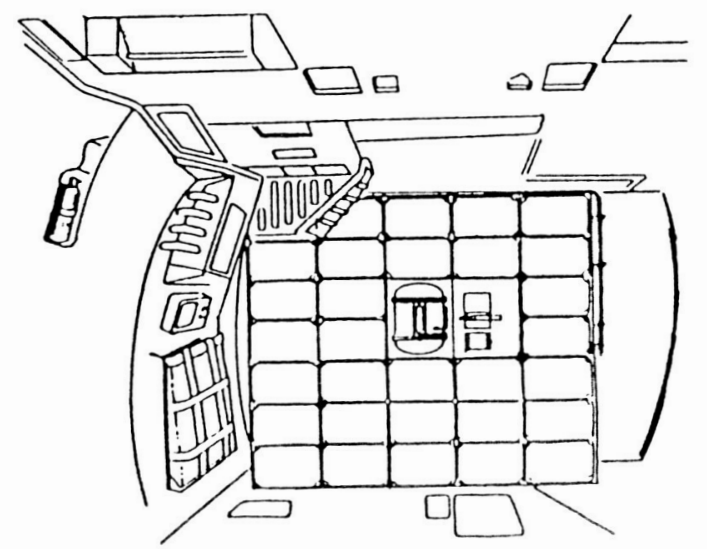

Figure 3 SSCE Middeck configuration. 


\section{ORIGINAL PAGE IS \\ OF POOR QUALITY}

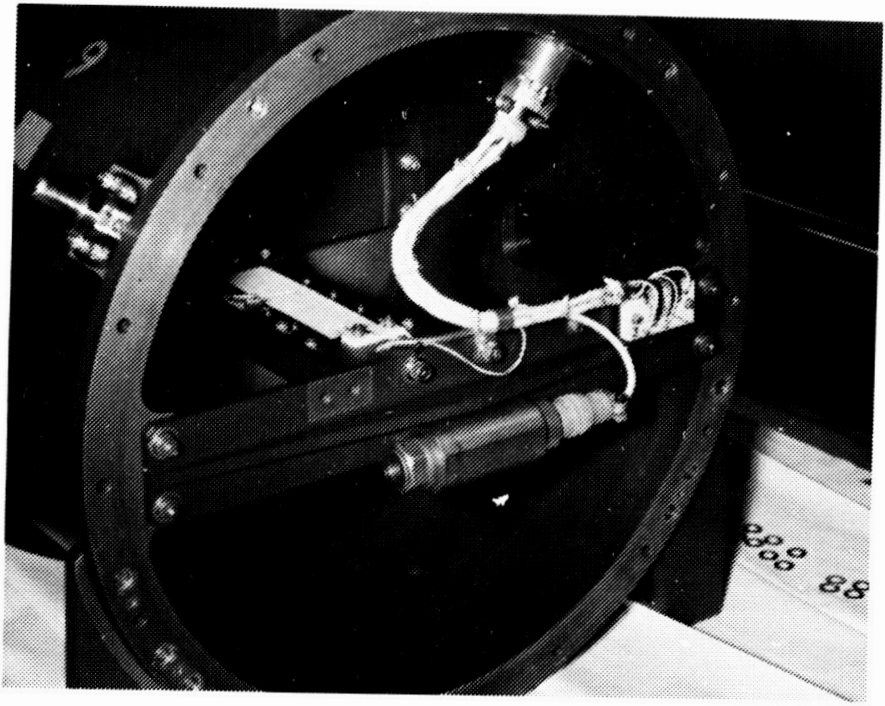

Figure 4 Chamber module with end removed.

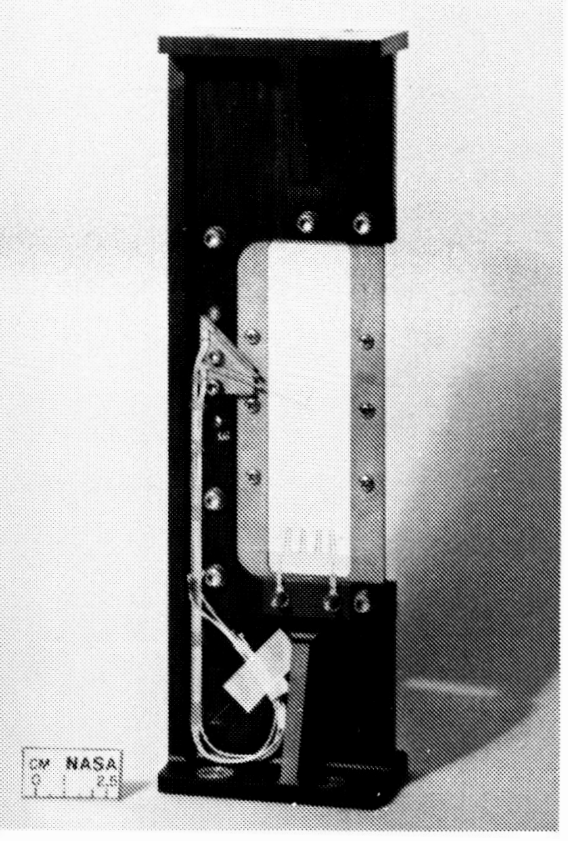

Figure 5 Paper sample holder.

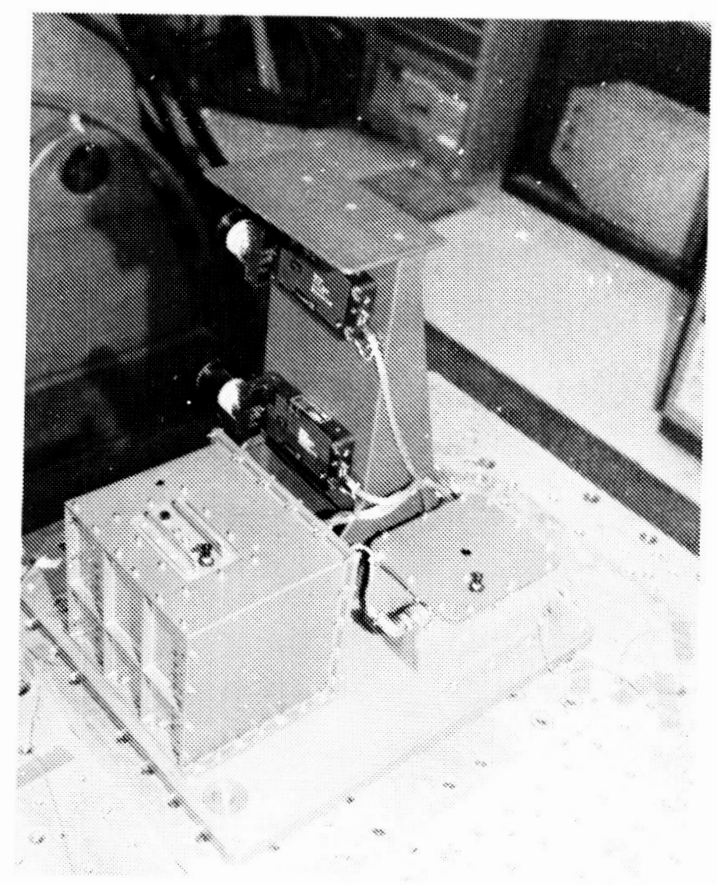

Figure 6 Camera module.

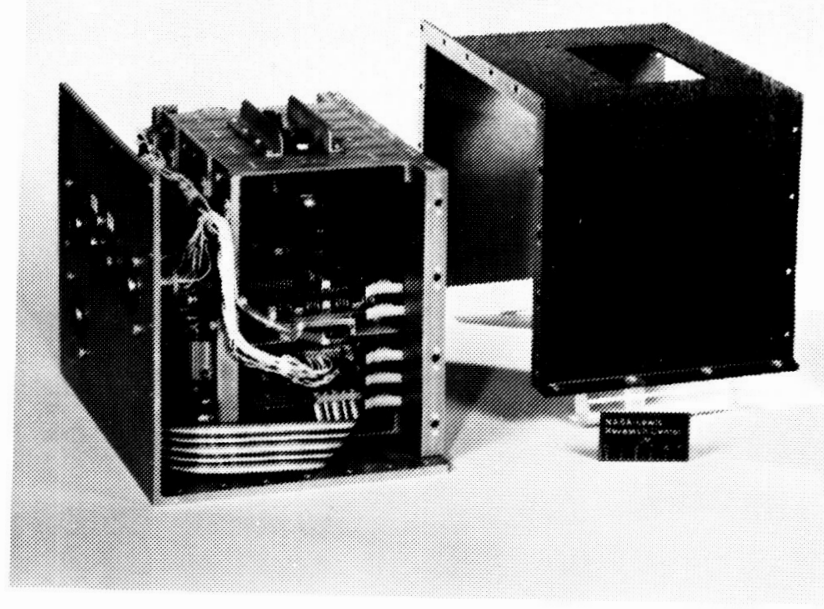

Figure 7 Electrical box with top removed. 


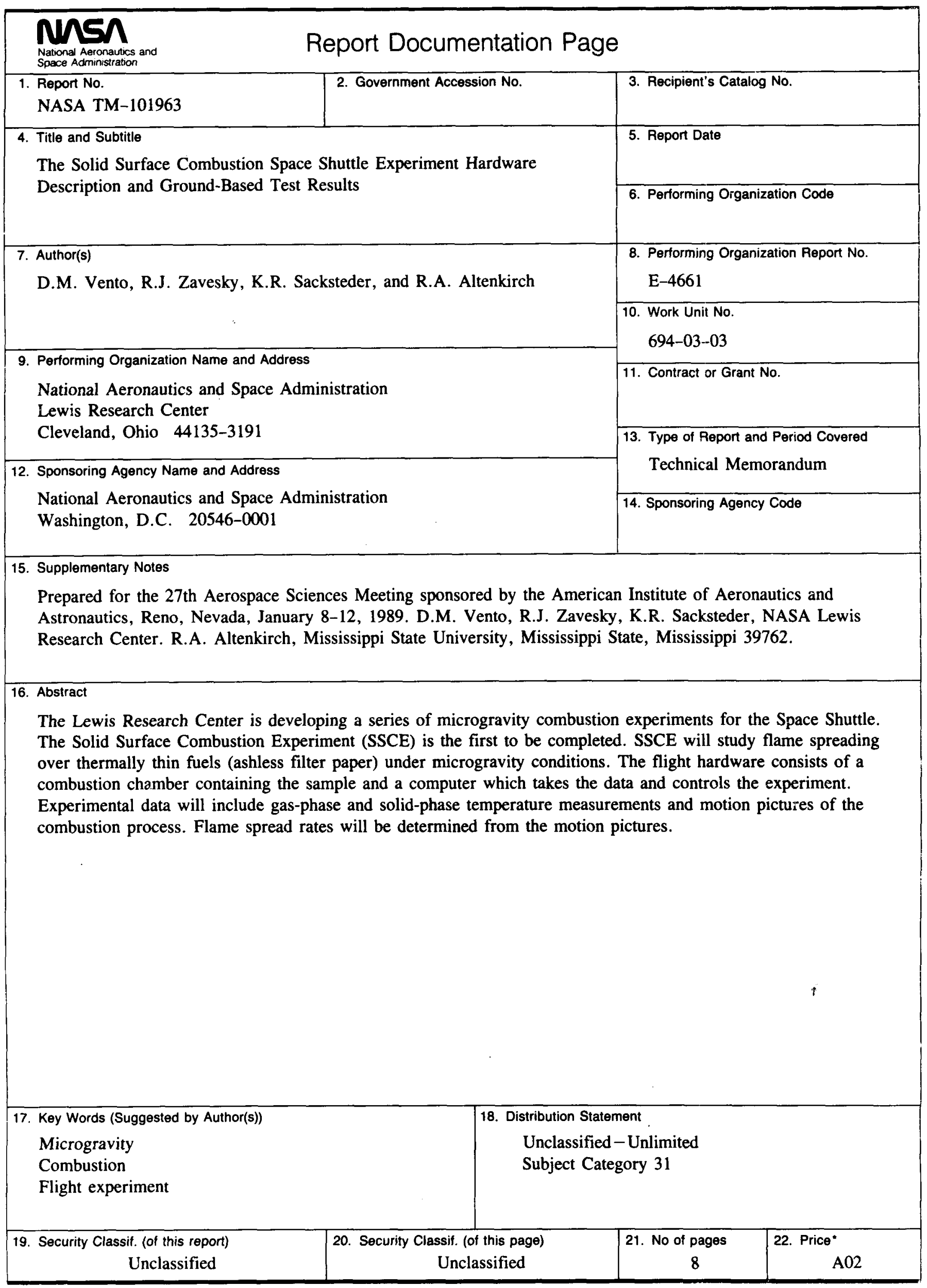

